\title{
CONCEPTUALIZACIÓN DE LA FUNCIÓN SOCIAL DE LA PROPIEDAD EN EL DERECHO ESPAÑOL Y COLOMBIANO ${ }^{1}$ Conceptualization of the Social Role of Property in Spanish and Colombian Law
}

\author{
$\underline{\text { Jimmy Antony Pérez Solano }}^{2}$
}

Fecha de Recepción: 10 de mayo de 2016

Fecha de Aceptación: 20 de mayo de 2016

SUMARIO: 1. Introducción; 2. La función social de la propiedad en el derecho español; 3. La función social de la propiedad en el derecho colombiano; 4. Convergencias y divergencias conceptuales en torno a la función social de la propiedad en el derecho español y colombiano; 5. Conclusiones; 6. Referencias Bibliográficas

\footnotetext{
${ }^{1}$ Este artículo es resultado de la investigación titulada La función social de la propiedad y la potestad expropiatoria del Estado en el derecho español y colombiano, realizada en la especialización en derecho administrativo en la Universidad de Salamanca, España, finalizada en 2015.

${ }^{2}$ Profesor e investigador de la División de Derecho de la Universidad del Norte. Abogado de la Universidad Nacional de Colombia y especialista en Derecho Privado-Económico de la misma universidad. Especialista en Gestión Pública e Instituciones Administrativas y Magister en Derecho Público para la Gestión Administrativa de la Universidad de Los Andes. Especialista en Derecho Administrativo y Financiero. Diploma de Estudios Avanzados -D.E.A.- y Doctorando en Derecho de la Universidad de Salamanca-España. E-mail: pjimmy@uninorte.edu.co
} 


\section{CÓMO SE CITA ESTE ARTÍCULO (Normas APA-6)}

Pérez Solano, Jimmy Antony (2016). Conceptualización de la función social de la propiedad en el derecho español y colombiano. Revista Jurídica Mario Alario D’Filippo, VIII (16), pág 176-191.

\section{RESUMEN}

El desarrollo histórico alrededor del concepto de la propiedad, en especial de la propiedad privada, y teniendo en cuenta el desarrollo del derecho y el papel que juega hoy en nuestras sociedades, nos Ileva a hacer una lectura de la propiedad privada en el marco de los Estados sociales de derecho. Son de nuestro interés, y para los fines pertinentes, los de España y Colombia, en un ejercicio de derecho comparado que tiene como finalidad dilucidar la función social de la propiedad privada en ambos Estados. El objetivo es lograr establecer semejanzas y diferencias que permitan concluir si la propiedad privada es o tiene una función social. Determinar si esta goza del estatus de derecho fundamental.

\section{PALABRAS CLAVE}

Propiedad, función social, derecho fundamental, acciones legales.

\section{ABSTRACT}

The historical development around the concept of property, especially private property, and taking into account the development of law and its role today in our societies, leads to a reading of private property under the social Rule of Law. In this essay we're interested in those of Spain and Colombia, in an exercise in comparative law that aims to clarify the social function of private property in both countries. The aim is to achieve establish similarities and differences to conclude whether private property is or has a social function. To decide if it has the status of a fundamental right.

\section{KEYWORDS}

Property, social function, fundamental right, legal action. 


\section{INTRODUCCIÓN}

La propiedad o el derecho de dominio sobre un bien recae y se desarrolla como el disfrute de un bien por parte de quien se hace llamar su propietario o dueño. Este disfrute le permite uso, explotación y disposición de la propiedad, incluso para su venta. Cabe mencionar que el derecho de propiedad o de dominio no sólo garantiza el disfrute de la cosa o bien, sino que además limita el uso y el goce a otras personas del bien en disputa. Sin embargo, a lo largo de la historia y el desarrollo jurídico, este derecho de dominio o de propiedad sobre los bienes que se categorizan como "privados" no ha tenido el mismo alcance. Dependiendo del tipo de Estado y el momento histórico en el que estemos, manejaremos un concepto diferente para el derecho de dominio o propiedad. Este desarrollo llevó a que la "propiedad privada" jugara un papel preponderante dentro de los Estados, en especial por la llamada función social de la propiedad privada, en donde se discute si en efecto esta última tiene una función social o es en sí misma una función social. Establecer esta diferencia conceptual al interior de nuestros sistemas jurídicos nos permitirá darle mayores alcances a su instrumentalización y protección.

\section{LA FUNCIÓN SOCIAL DE LA PROPIEDAD EN EL DERECHO ESPAÑOL}

Para efectos de vislumbrar lo que se entiende como función social de la propiedad es preciso detenernos primeramente en el concepto mismo de propiedad, el cual ha ido cambiando de acuerdo con los diferentes momentos históricos. Se rememora, en primer término, la propiedad quiritaria, propia de los primitivos ciudadanos romanos que se regían por el ius civil, así como la propiedad bonitaria, propia de ciudadanos romanos que no pertenecían a las antiguas familias de la urbe, y la propiedad peregrina reconocida por obra del Pretor (Calvo, 2000) Posteriormente, en la edad media, para el manejo de la propiedad el Señor Feudal ejercía potestades jurídicas sobre el suelo, las propiedades y sobre quienes allí se encontraban, de tal forma que aquél se convertía en dominus de cuanto allí hubiere. En la edad moderna se tiene un nuevo concepto de propiedad privada y, con él, un nuevo concepto de sociedad (García, 2007) Imperaban en ella las posturas liberal-individualistas en torno al derecho de dominio desde un derecho subjetivo puro que se fue matizando con teorías de corte más socialista, culminando con el concepto actual imperante, en el que se conjugan dos posturas antagónicas pero coexistentes como son la concepción liberal-individualista y la concepción social o colectiva. La concepción liberal fue la imperante entre los siglos XVIII y XIX, donde la Nación tiene el deber de proteger la propiedad y demás derechos de los individuos que la componen. Esto fue característico de la Constitución de $1812^{3}$. La concepción social fue la imperante a partir de la Constitución de $1931^{4}$, donde se da un mayor intervencionismo estatal en la economía, subordinando los intereses privados a los de la economía nacional.

\footnotetext{
3 "Artículo 4: La Nación está obligada a conservar y proteger por leyes sabias y justas la libertad civil, la propiedad, y los demás derechos legítimos de todos los individuos que la componen."

4 “Artículo 44: Toda la riqueza del país, sea quien fuere su dueño, está subordinada a los intereses de la economía nacional y afecta al sostenimiento de las cargas públicas, con arreglo a la Constitución y a las leyes. La propiedad de toda clase de bienes podrá ser objeto de expropiación forzosa por causa de utilidad social mediante adecuada indemnización, a menos que disponga otra cosa una ley aprobada por los votos de la mayoría absoluta de las Cortes. Con los mismos requisitos la propiedad podrá ser socializada"
} 
Es dentro de este marco histórico-normativo como se gestó el actual marco, condensado en el artículo 33 de la Constitución Española de 1978, en el que encontramos la fuente conceptual del derecho de propiedad. Aquí se recogen y superan las dos concepciones anteriores en un mismo texto normativo, pero desde una nueva idea del Estado y los derechos subyacentes, como es el Estado social y democrático de derecho. Se pregona en el artículo 1.1 de la Constitución Española ${ }^{5}$, en el que:

Parten del reconocimiento de la propiedad privada y la libertad de empresa [C.E., 1978, art. 38] en el contexto de la economía capitalista. Pero, a la vez, limitan los efectos perniciosos del sistema capitalista mediante el reconocimiento de una serie de derechos de contenido económico, social y cultural [C.E., 1978, Capítulo III del Título I] y el reconocimiento de la intervención de los poderes públicos en la economía [arts. 128 y ss. C.E.] (García, 2007, p. 288).

Ahora bien, precisada la actual concepción ideológica de la propiedad en el rango constitucional español, es preciso dilucidar su función social en los términos del artículo 33 anotado, al punto de establecer si él mismo, efectivamente, tiene la característica de derecho fundamental, dada la trascendencia que ello tiene en torno de sus garantías y tutela judicial efectiva. Algunos doctrinantes consideran que el derecho a la propiedad en España es un derecho fundamental, como es el caso de García $(2007)^{6}$, que sobre el particular ha manifestado que:

Derechos fundamentales son aquellos derechos subjetivos que fundamentan el orden político, social y económico de convivencia, de tal manera que cabría considerar como derechos fundamentales todos aquellos que se disciplinan en el Capítulo II del Título I de la Constitución (derechos y libertades), con independencia del nivel de garantías que cada uno de ellos presente (p. 288).

No es necesario para que sea reconocido como tal, por tanto, que éste deba estar incluido en la sección primera del Capítulo II del Título I de la Constitución, con las respectivas garantías que le son propios a esos derechos. En su lugar, el derecho a la propiedad goza de otras garantías constitucionales consagradas en los artículos: $24,53.1$, literales a, b y c, 86.1 y 161.1 a , así como la protección judicial ante la jurisdicción internacional.

De igual manera, y sin perder el carácter de fundamental, el derecho de propiedad está desprovisto de las garantías reservadas para los derechos consagrados en la sección primera del Capítulo II del Título I de la Constitución, esto es, las consagradas en los artículos 53.1, 53.2 y 168. Si bien el Convenio Europeo para la Protección de los Derechos Humanos y de las Libertades Fundamentales, hecho en Roma el 4 de noviembre de 1950, no incluyó al de propiedad entre los derechos que garantiza, sí lo hizo con posterioridad

\footnotetext{
5 "Artículo 1. España se constituye en un Estado social y democrático de derecho, que propugna como valores superiores de su ordenamiento jurídico la libertad, la justicia, la igualdad y el pluralismo político".

${ }^{6}$ En ese mismo sentido se pronunció el profesor Marco Fernando Pablo al referirse al derecho de propiedad, en las clases de los 370 Cursos de Especialización en Derecho Administrativo.
} 
en el Protocolo Adicional hecho en París el 20 de marzo de 1952, en cuyo artículo 1 se establece:

Toda persona física o moral tiene derecho al respeto de sus bienes. Nadie podrá ser privado de su propiedad sino por causa de utilidad pública y en las condiciones previstas por la Ley y los principios generales del Derecho Internacional.

Las disposiciones precedentes se entienden sin perjuicio del derecho que poseen los Estados de poner en vigor las leyes que juzguen necesarias para la reglamentación del uso de los bienes de acuerdo con el interés general o para garantizar el pago de los impuestos u otras contribuciones o de las multas (Barcelona, 2013, p. 7).

Es evidente que este Protocolo fue más allá de lo que dispuso sobre el derecho a la propiedad el artículo 17 del texto de la Declaración Universal de Derechos Humanos de las Naciones Unidas de 1948, cuando estableció de forma lacónica: "1. Toda persona tiene derecho a la propiedad, individual y colectivamente. 2. Nadie será privado arbitrariamente de su propiedad". Además de lo anterior, es primordial vislumbrar este derecho fundamental dentro del marco de la función social que tiene la propiedad en la Constitución Española. Ello es así en tanto que para poder comprender todas las dimensiones de este derecho debe hacerse desde los preceptos constitucionales, de manera que la "propiedad" (pública o privada) sea analizada inescindiblemente desde lo dispuesto en el artículo 33 de la Constitución española, el cual establece:

1. Se reconoce el derecho a la propiedad privada y a la herencia. 2. La función social de estos derechos delimitará su contenido, de acuerdo con las leyes. 3. Nadie podrá ser privado de sus bienes y derechos sino por causa justificada de utilidad pública o interés social, mediante la correspondiente indemnización y de conformidad con lo dispuesto por las leyes (subrayado fuera de texto).

La función social de la propiedad en el derecho español, establecida en el citado precepto constitucional, se puede mirar desde múltiples posturas doctrinales, entre las cuales tenemos:

1) El derecho de propiedad es meramente subjetivo y por lo mismo la función social no es más que un concepto programático u orientador de la figura, pero sin aplicación material en la vida práctica.

2) El derecho de propiedad es subjetivo, pero condicionado al ejercicio de otros derechos colectivos y por lo tanto no debe lesionar intereses sociales. "Esta dirección doctrinal vendría a condensarse en la máxima siguiente: la propiedad tiene una función social, pero no es una función social" (García, 2007, p. 293)

3) El derecho de propiedad no es sólo subjetivo. Va más allá en tanto que conlleva una serie de derechos y deberes que pueden ir o no en consonancia con sus intereses individuales $y$, en todo caso, estar cargada de limitaciones en su ejercicio y condicionados por los deberes colectivos por el solo hecho de hacer parte de un todo social. 
Nótese que el Código Civil español define la propiedad como "el derecho a gozar y disponer de una cosa, sin más limitaciones que las establecidas en las leyes" (Artículo 348) Frente a esto, el Tribunal Constitucional Español en consonancia con la tercera postura doctrinal arriba mencionada, mediante Sentencia 37/1987 de 26 de marzo, expresó:

Su contenido esencial no puede hacerse desde la exclusiva consideración subjetiva del derecho o de los intereses individuales que a éste subyacen, sino que debe incluir igualmente la necesaria referencia a la función social, entendida, no como mero límite externo a la definición de su ejercicio, sino como parte integrante del derecho mismo.

En esa misma providencia, el Tribunal Constitucional refuerza la idea al expresar que:

La referencia a la "función social" como elemento estructural de la definición misma del derecho a la propiedad privada o como factor determinante de la delimitación legal de su contenido, pone de manifiesto que la Constitución no ha recogido una concepción abstracta de este derecho como mero ámbito subjetivo de libre disposición o señorío sobre el bien objeto del dominio reservado a su titular, sometido únicamente en su ejercicio a las limitaciones generales que las Leyes impongan para salvaguardar los legítimos derechos o intereses de terceros o del interés general. Por el contrario, la Constitución reconoce un derecho a la propiedad privada que se configura y protege, ciertamente, como un haz de facultades individuales sobre las cosas, pero también, y al mismo tiempo, como un conjunto de deberes y obligaciones establecidos, de acuerdo con las Leyes, en atención a valores o intereses de la colectividad, es decir, a la finalidad o utilidad social que cada categoría de bienes objeto de dominio esté llamada a cumplir.

Finalmente, el Tribunal Constitucional en el fallo comentado dejó claro que:

La fijación del "contenido esencial" de la propiedad privada no puede hacerse desde la exclusiva consideración subjetiva del derecho o de los intereses individuales que a éste subyacen, sino que debe incluir igualmente la necesaria referencia a la función social, entendida no como mero límite externo a su definición o a su ejercicio, sino como parte integrante del derecho mismo. Utilidad individual y función social definen, por tanto, inescindiblemente el contenido del derecho de propiedad sobre cada categoría o tipo de bienes (STC 37/1987 de 26 de marzo. BOE N 89 del 14 de abril de 1987).

Valga decir que la función social de la propiedad, resumida en el artículo 33.2 de la Constitución Española, dispone que sean las leyes las que modulen el derecho de propiedad privada en función de intereses sociales superiores, de manera que puedan limitarse siempre que se mantenga su núcleo esencial. En tales eventos procederá el deber de indemnizar.

No obstante ser el Código Civil español la norma de rango legal que mejor encarna la voluntad constitucional, no debe perderse de vista que en el ordenamiento jurídico español existen otras normas que han complementado y le han dado fuerza material a los postulados constitucionales sobre la materia. Es el caso de la Ley de 16 de diciembre 
de 1954 conocida como ley de expropiación forzosa, el Decreto de 26 de abril de 1957, mediante el cual se aprueba el reglamento de la ley de expropiación forzosa, así como todas aquellas relativas a las expropiaciones. Consideramos, sin embargo, que es con el Código Civil que se fijan las bases de las normas especiales que con posterioridad han venido regulando la materia.

En efecto, el Código Civil español (Real Decreto de 24 de julio de 1889), al referirse a la institución de la propiedad en los artículos 348 al 352, la definió de la siguiente manera: "La propiedad es el derecho de gozar y disponer de una cosa, sin más limitaciones que las establecidas en las leyes. El propietario tiene acción contra el tenedor y el poseedor de la cosa para reivindicarla" (art. 348) Ahora bien, como garantía de protección de este derecho, el Código Civil dispuso en su artículo 349 que: "Nadie podrá ser privado de su propiedad sino por Autoridad competente y por causa justificada de utilidad pública, previa siempre la correspondiente indemnización. Si no procediere este requisito, los Jueces ampararán y, en su caso, reintegrarán en la posesión al expropiado". Esto implica que hay garantía del derecho a la propiedad tanto para el individuo como para la colectividad, en su componente de función social en lo que atañe a una justificada utilidad pública. Se concilia así la correspondiente indemnización cuando haya lugar a éste. Finalmente, la norma en estudio pone de presente que: "El propietario de un terreno es dueño de su superficie y de lo que está debajo de ella, y puede hacer en él las obras, plantaciones y excavaciones que le convengan, salvas las servidumbres, y con sujeción a lo dispuesto en las leyes sobre Minas y Aguas y en los reglamentos de policía" (art. 350).

\section{LA FUNCIÓN SOCIAL DE LA PROPIEDAD EN EL DERECHO COLOMBIANO}

De acuerdo con la Corte Constitucional colombiana:

Puede definirse a la propiedad privada como el derecho real que se tiene por excelencia sobre una cosa corporal o incorporal, que faculta a su titular para usar, gozar, explotar y disponer de ella, siempre y cuando a través de su uso se realicen las funciones sociales y ecológicas que le son propias. (Corte Constitucional, Sala Plena, Sentencia C-189, 2006).

En el derecho colombiano la propiedad privada goza de protección constitucional, y es así como el artículo 58 de la Carta Fundamental dispone que "se garantizan la propiedad privada y los demás derechos adquiridos con arreglo a las leyes civiles, los cuales no pueden ser desconocidos ni vulnerados por leyes posteriores". Como es de natural, esta protección constitucional se concreta en las normas de rango legal que regulan la figura de la propiedad en el resto del ordenamiento jurídico, como es el caso del Código Civil colombiano (Ley 57 de 1887), en el que se establece que "el dominio que se llama también propiedad es el derecho real en una cosa corporal, para gozar y disponer de ella arbitrariamente $^{7}$, no siendo contra ley o contra derecho ajeno" (art. 669).

7 El adverbio "arbitrariamente" subrayado, fue declarado inexequible por la Corte Constitucional colombiana mediante Sentencia C-595 de agosto 18 de 1999, por considerar que

[I]a propiedad, en tanto que derecho individual, tiene el carácter de fundamental, bajo las particulares condiciones que ella misma 
Sin embargo, la misma Constitución Política dispone en el mencionado artículo 58 que "cuando de la aplicación de una ley expedida por motivos de utilidad pública o interés social, resultaren en conflicto los derechos de los particulares con la necesidad por ella reconocida, el interés privado deberá ceder al interés público o social". Esto implica que el derecho de propiedad en Colombia no es absoluto, exclusivo o perpetuo, como tradicionalmente se ha atribuido a la propiedad privada en países de tradición romanogermánica en contraposición al sistema jurídico socialista. En efecto, el propietario de un bien inmueble tiene su derecho limitado por el respeto al ejercicio del derecho de los demás, especialmente enmarcado dentro de los límites el interés común, esto es, de la sociedad en su conjunto. Es el caso, a manera de ejemplo, de las restricciones urbanísticas respecto del alto de las paredes divisorias entre predios vecinos, o la ubicación de ventanas o balcones con vista a los predios colindantes, o los límites a las líneas de construcción en relación con las edificaciones vecinas, o el respeto por el área mínima del antejardín de cada predio urbano, entre otros. Se presentan restricciones al derecho de propiedad de todos los habitantes del país con miras a lograr la armonización y convivencia de todos los derechos ejercidos concurrentemente en una comunidad y, por lo mismo, no hay indemnizaciones ante tales eventos.

Ahora bien, mencionamos que el derecho de propiedad no es exclusivo en tanto que, en procura de la convivencia de derechos, en ocasiones se hace necesario que se establezcan limitaciones o gravámenes a la propiedad. De esta manera los otros también pueden ejercer su derecho limitado, como es el caso de la imposición de servidumbres de tránsito. De igual manera dijimos que el derecho de propiedad no era perpetuo, salvo que tuviera lugar una prescripción adquisitiva por abandono en el uso de la propiedad, con la correspondiente posesión ejercida por algún sujeto por el tiempo y bajo las condiciones que establezca la ley para hacerse propietario. Todo lo anterior cobra sentido en la medida en que la propiedad tiene una función social que implica obligaciones con los demás habitantes del territorio en torno al ejercicio de ese derecho. La Constitución Política en el artículo 58, igualmente dispone que:

Por motivos de utilidad pública o de interés social definidos por el legislador, podrá haber expropiación mediante sentencia judicial e indemnización previa ${ }^{8}$ Esta se fijará consultando los intereses de la comunidad y del afectado. En los casos que determine el legislador, dicha expropiación podrá adelantarse por vía administrativa, sujeta a posterior acción contenciosa-administrativa, incluso respecto del precio.

ha señalado. Justamente los atributos de goce y disposición constituyen el núcleo esencial de ese derecho, que en modo alguno se afecta por las limitaciones originadas en la ley y el derecho ajeno pues, contrario sensu, ellas corroboran las posibilidades de restringirlo, derivadas de su misma naturaleza, pues todo derecho tiene que armonizarse con las demás que con él coexisten, o del derecho objetivo que tiene en la Constitución su instancia suprema. Por esas consideraciones, la Corte procederá a retirar el término arbitrariamente (referido a los atributos del derecho real de propiedad en Colombia) del artículo 669 del Código Civil, demandado.

${ }^{8}$ No obstante lo anterior, y siendo esa la regla general, el artículo 59 de la Carta Fundamental dispone que "En caso de guerra y sólo para atender a sus requerimientos, la necesidad de una expropiación podrá ser decretada por el Gobierno Nacional sin previa indemnización. En el expresado caso, la propiedad inmueble sólo podrá ser temporalmente ocupada, para atender a las necesidades de la guerra, o para destinar a ella sus productos. El Estado será siempre responsable por las expropiaciones que el Gobierno haga por sí o por medio de sus agentes." 
Esto cobra sentido en la medida en que, no solamente el derecho de propiedad puede verse limitado por necesidades del ejercicio del derecho de propiedad por parte de otro particular integrante de la comunidad, sino que puede ser requerido por el Estado mismo para el cumplimiento de sus fines. Ya sea para construir bienes de uso público tales como parques, vías o acueductos, etc., o para construir edificaciones para el funcionamiento de las entidades estatales, conocidos como bienes fiscales. Todo ello, claro está, para fines de utilidad pública o de interés social definido por el legislador ${ }^{9}$

Tal como se mencionó renglones atrás, de acuerdo con el artículo 58 de la Constitución Política colombiana, "la propiedad es una función social que implica obligaciones. Como tal, le es inherente una función ecológica". Esa función social la ha definido la Corte Constitucional en diferentes pronunciamientos, entre los cuales se pone de presente la Sentencia C-595 de 18 de agosto de 1999, en la cual se expresa:

La función social de la propiedad presenta diversas y matizadas caracterizaciones, las cuales están determinadas por la naturaleza de los bienes, su clase, y la entidad que es titular de los derechos que de ella emanan, así como también por la posición económica de las personas que la poseen. La función social tiene, por una parte, el significado de moderar y restringir el alcance del derecho de propiedad, mientras que por otra parte, le corresponde el de implicar una mayor afirmación de ciertas clases de propiedad.

Así mismo, la Corte Constitucional se pronunció mediante Sentencia C-536 de 23 de octubre de 1997 en la cual se expresó:

Como es sabido, atendiendo al sentido y alcance del artículo 58 de la Constitución, la adquisición y ejercicio de la propiedad privada puede ser susceptible de una serie de condicionamientos y cargas impuestos por el Estado, en razón de que la propiedad no se concibe como un derecho absoluto sino relativo, lo cual se deriva del principio constitucional solidarista de que <<la propiedad es una función social que implica obligaciones >>

Sin embargo, autores como el Dr. Luis Guillermo Velásquez Jaramillo (2010) al referirse a la función social de la propiedad expresan:

En realidad, la propiedad en Colombia tiene una función social, y no es una función social como lo preceptúa la norma constitucional. La propiedad es función social cuando pertenece en su totalidad al Estado sin permitir la titulación en manos privadas o

\footnotetext{
${ }^{9}$ En ese sentido, la Corte Constitucional, mediante Sentencia C-216 de 9 de junio de 1993, se pronunció:

La conversión de la propiedad privada en pública por motivos de utilidad pública o de interés social, que es lo característico de la expropiación, es una consecuencia derivada de la concurrencia de tales razones -genéricamente previstas por el legislador en un caso concreto, como culminación de un proceso y mediante sentencia judicial e indemnización previa, salvo las excepciones que la Carta Política establece-, de tal manera que no se aplica a título de sanción por la conducta del propietario sino en desarrollo del principio constitucional de prevalencia del interés común sobre el particular, que debe ceder ante aquel en caso de conflicto. La confiscación y la extinción del dominio son sanciones aplicadas al propietario, pero tampoco tienen idéntico sentido ni obedecen a las mismas causas. La primera - excluida de nuestro ordenamiento jurídico- representa el absoluto despojo de la propiedad por acto del Estado que se impone a título de pena y sin compensación alguna. La segunda, que en el actual sistema tiene varias expresiones, se produce a raíz de la realización de ciertos supuestos de hecho establecidos por el Constituyente o el legislador.
} 
particulares (propiedad socialista), y tiene función social cuando se acepta su titularidad en un propietario particular con la carga de hacer primar sobre su derecho el interés público o social (p. 199).

No obstante esta aparente disparidad de criterios respecto a que si la propiedad es o tiene una función social, consideramos que la posición jurisprudencial y la doctrinal comparten un mismo sentido. Ahora bien, en lo que concierne a la función ecológica de la propiedad debemos acudir a lo regulado en la Ley 99 de 1993, "por la cual se crea el Ministerio del Medio Ambiente, se reordena el Sector Público encargado de la gestión y conservación del medio ambiente y los recursos naturales renovables, se organiza el Sistema Nacional Ambiental, SINA, y se dictan otras disposiciones", conocida también como "Ley del Medio Ambiente", que, al referirse a la función social y a la función ecológica de la propiedad , dispone:

Utilidad Pública e Interés Social, Función Ecológica de la Propiedad. Decláranse de utilidad pública e interés social la adquisición por negociación directa o por expropiación de bienes de propiedad privada, o la imposición de servidumbres, que sean necesarias para la ejecución de obras públicas destinadas a la protección y manejo del medio ambiente y los recursos naturales renovables, conforme a los procedimientos que establece la ley.

Las normas ambientales son de orden público y no podrán ser objeto de transacción o de renuncia a su aplicación por las autoridades o por los particulares. En los términos de la presente Ley el Congreso, las Asambleas y los Concejos municipales y distritales quedan investidos de la facultad de imponer obligaciones a la propiedad en desarrollo de la función ecológica que le es inherente. Son motivos de utilidad pública e interés social para la adquisición, por enajenación voluntaria o mediante expropiación, de los bienes inmuebles rurales o urbanos, patrimoniales de entidades de derecho público o demás derechos que estuvieren constituidos sobre esos mismos bienes; además de los determinados en otras leyes, los siguientes:

- La ejecución de obras públicas destinadas a la protección y manejo del medio ambiente y los recursos naturales renovables.

- La declaración y alinderamiento de áreas que integren el Sistema de Parques Nacionales Naturales.

- La ordenación de cuencas hidrográficas con el fin de obtener un adecuado manejo de los recursos naturales renovables y su conservación (art. 107).

El ejercicio del derecho de propiedad impone el ejercicio de una función social y su incumplimiento puede dar lugar a la iniciación de un proceso de enajenación forzosa de su propiedad. Así lo establece la Ley 388 de $1997^{10}$, cuando expresa:

${ }^{10}$ Modificatoria de la Ley 9 de 1989 "por la cual se dictan normas sobre planes de desarrollo municipal, compraventa y expropiación de bienes y se dictan otras disposiciones". 
Desarrollo y construcción prioritaria. A partir de la fecha de vigencia de esta Ley, habrá lugar a la iniciación del proceso de enajenación forzosa en pública subasta, por incumplimiento de la función social de la propiedad sobre:

1. Los terrenos localizados en suelo de expansión, de propiedad pública o privada, declarados como de desarrollo prioritario, que no se urbanicen dentro de los tres (3) años siguientes a su declaratoria.

2. Los terrenos urbanizables no urbanizados localizados en suelo urbano, de propiedad pública o privada, declarados como de desarrollo prioritario, que no se urbanicen dentro de los dos (2) años siguientes a su declaratoria.

3. Los terrenos o inmuebles urbanizados sin construir, localizados en suelo urbano, de propiedad pública o privada, declarados como de construcción prioritaria, que no se construyan dentro de los dos (2) años siguiente a su declaratoria ${ }^{11}$

4. Adicionado por el art. 64, Ley 1537 de 2012. "Lo anterior sin perjuicio de que tales inmuebles pueden ser objeto de los procesos de enajenación voluntaria y expropiación de que trata la presente Ley."

Parágrafo.- La declaratoria de desarrollo o construcción prioritaria estará contenida en el programa de ejecución, de conformidad con las estrategias, directrices y parámetros previstos en el plan de ordenamiento territorial, de acuerdo con los objetivos establecidos en el plan para el logro de su cumplimiento. En todo caso esta declaratoria podrá preverse directamente en el contenido del plan de ordenamiento (art. 52).

En ese mismo sentido se pronunció el Subdirector de Conceptos de la Secretaría General de la Alcaldía Mayor de Bogotá D.C., Salomón García Pineda (2006), al absolver una consulta sobre el tema en estudio:

En primer lugar debe observarse, que es imprecisa la inquietud pues lo que se declara es la existencia de condiciones de utilidad pública o interés social para la "adquisición" del inmueble y no que el inmueble tenga esas calidades, pues la utilidad pública o el interés social se constituye sobre la necesidad del Estado de acceder a la propiedad de un inmueble que requiere para unos fines específicos, pudiendo expropiar sino hay enajenación voluntaria. De tal manera que lo que califica si la adquisición es por "utilidad pública" o por "interés social" es el fin para el cual se necesita el predio.

$Y$ es precisamente esa importancia que reviste para el Estado la adquisición de un inmueble, la que conlleva a que el inmueble deba ser excluido del comercio, situación que no opera de plano con la sola expedición del oficio o acto que declara la existencia de interés o utilidad, por la adquisición del inmueble o por su expropiación administrativa, pues exige que este sea inscrito por la entidad adquirente o expropiante, en la Oficina de Registro de Instrumentos Públicos dentro de los cinco (5) días hábiles siguientes a su ejecutoria, tal y como lo prevén el inciso 5o del artículo 13 de la Ley 9 de 1989, para el caso de la enajenación voluntaria previa expropiación judicial y el artículo 66 de la Ley 388 de 1997, para la expropiación administrativa.

\footnotetext{
${ }^{11}$ El numeral 3 fue corregido mediante FE DE ERRATAS publicada en el Diario Oficial No. 43.127 del 12 de septiembre de 1997 en cuanto a cambiar el término establecido que ya no es de un año sino: "dentro de los dos (2) años siguientes a su declaratoria".
} 
En este punto valdría la pena indagar si en el derecho colombiano se tiene el de propiedad como un derecho fundamental. En este sentido la respuesta está dada por la jurisprudencia de la Corte Constitucional, pero con ciertos matices que merecen ser mencionados. En principio el derecho a la propiedad no es derecho fundamental ya que es considerado de naturaleza económica y social. Sin embargo, en diversos pronunciamientos ha expresado que el de propiedad es fundamental por conexidad. En efecto, la Corte Constitucional (2011) se pronunció en ese sentido precisando que:

Para que proceda la protección inmediata y efectiva del derecho a la propiedad por vía de tutela, debe su desconocimiento afectar derechos que por naturaleza son fundamentales, como la vida, la integridad física, el trabajo, etc. En este contexto, sólo la conexidad entre el derecho a la propiedad privada y alguno de los derechos fundamentales esenciales en el desarrollo y ejercicio de las condiciones básicas de vida, permiten al juez de tutela, resolver un asunto de esta índole. La Corte ha entendido que la propiedad, por ser un derecho de naturaleza económico y social, su connotación de "fundamental" dependerá del estudio que el juez constitucional realice en el caso concreto (Corte Constitucional, Sala Séptima, Sentencia T-580/11,2011).

De igual manera, la Corte (2005) en otros fallos se ha referido al tema de la conexidad del derecho de propiedad con los derechos fundamentales y por esa vía garantiza su protección por el mecanismo excepcional de la Acción de Tutela, al expresar:

El derecho a la propiedad solo podrá ser protegido y garantizado por vía de la acción de tutela, siempre y cuando de la protección que por esta vía judicial se haga, se garantice igualmente el pleno ejercicio de otros derechos, estos si catalogados como fundamentales. La afectación del derecho a la propiedad tiene incidencia directa en el efectivo goce y respeto de otros derechos que como la vivienda digna, el trabajo, el mínimo vital y la propia vida entre otros, imponen el deber al juez constitucional de garantizar la protección oportuna del derecho a la propiedad privada, por consolidarse que entre éste y otros derechos de carácter fundamental existe una inescindible conexidad. En estos eventos, la propiedad privada como derecho, adquiere la connotación de derecho fundamental y por ello mismo merece la protección constitucional representada en la acción de tutela, que ese caso concreto se constituye en el mecanismo judicial óptimo (Sala Primera, Sentencia T-1321/05,2005).

\section{CONVERGENCIAS Y DIVERGENCIAS CONCEPTUALES EN TORNO A LA FUNCIÓN SOCIAL DE LA PROPIEDAD EN EL DERECHO ESPAÑOL Y COLOMBIANO}

En España el derecho de la propiedad se tiene como un derecho fundamental pero desprovisto de las garantías reservadas para los derechos consagrados en la sección primera del Capítulo II del Título I de la Constitución. Estas garantías corresponden a los artículos 53.1 (La reserva de ley orgánica en su regulación); 53.2 (Tutela preferente y sumaria por parte de los Jueces y Tribunales y el recurso de amparo ante el Tribunal Constitucional) y 168 (Protección mediante el mecanismo agravado de reforma constitucional) En 
Colombia, el de propiedad no es considerado derecho fundamental ya que se precisa como de naturaleza económica y social. Sin embargo, por la vía de la jurisprudencia de la Corte Constitucional, este se ha manifestado como un derecho fundamental por conexidad, en la medida en que su desconocimiento pueda afectar derechos que por naturaleza son fundamentales como la vida, la integridad física, el trabajo, entre otros. Por esta vía sí goza de la Acción Constitucional de Tutela que, guardada las proporciones, es equivalente (con sus pequeñas diferencias) al recurso de amparo ante el Tribunal Constitucional. La principal diferencia es que en Colombia se puede hacer ante cualquier juez, por existir un sistema difuso de garantías constitucionales.

Tanto en España como en Colombia la función social es la que causaliza el derecho de propiedad, pero la función social va más allá y delimita el derecho de propiedad y permite excluir ciertas facultades. Por ejemplo, la ley puede excluir el ius utendi, limitar si puede o no ser alquilada o afectar la propiedad a través de medidas que impidan fumar dentro de un establecimiento privado que preste servicios al público. Dicho de otra manera, en ambos ordenamientos jurídicos es permitido extraer atributos clásicos de la propiedad sin que exista propiamente una expropiación, sino simplemente una limitación o delimitación al ejercicio del derecho, sin que con ello se deba indemnizar por no afectar el núcleo básico del derecho de propiedad.

Tanto en el derecho español como en el colombiano se preserva y garantiza el derecho de los ciudadanos a la motivación, coherencia y congruencia de las decisiones administrativas, en especial cuando se trata de subordinar el de la propiedad privada por motivo de utilidad pública o el interés general. Cuanto mayor es la discrecionalidad de las decisiones administrativas, mayores deben ser las motivaciones.

\section{CONCLUSIONES}

- El concepto de propiedad obedece a cada momento histórico y se moldea de acuerdo con las necesidades sociales de cada tiempo.

- La Función Social de la propiedad es un presupuesto esencial de la potestad expropiatoria. Por consiguiente dicha potestad del Estado la otorga el hecho de que la "propiedad privada" no es absoluta y el disfrute de la misma puede ser limitada en beneficio de fines mayores. Ahora bien si decimos que la propiedad privada es una función social en sí misma, podríamos darle el carácter de derecho fundamental, por lo que, a través de las acciones establecidas para su defensa, el Estado podrá ejercerla dentro del respeto que imponen los derechos fundamentales. Por lo tanto, teniendo en cuenta que la propiedad privada es una función social, el Estado permite el goce al particular del derecho de dominio, pudiéndolo retomar en cualquier momento. Mientras, cuando la propiedad privada tiene una función social, se ejerce el derecho de dominio por parte de los particulares (aunque limitado) y el mismo es protegido por la Constitución y las leyes, aun cuando no tendría explícitamente el carácter de 
derecho fundamental Se limita, igualmente, la acción del Estado para su disposición, al tener que someter la expropiación de un bien a la ocurrencia de determinadas circunstancias y a acudir a una serie de procedimientos administrativos o judiciales para hacer efectiva la expropiación o limitación del derecho de dominio de un particular en beneficio de un interés colectivo. Luego se procede con el consecuencial pago de las indemnizaciones, cuando a ello hubiere lugar.

\section{REFERENCIAS BIBLIOGRÁFICAS}

Asamblea General de las Naciones Unidas. (1948) Declaración Universal de los Derechos Humanos. París: ONU. Recuperado de: http://www.un.org/es/universaldeclaration-human-rights/

Barcelona, J. (2013). Propiedad, privación de la propiedad y expropiación en el sistema del Convenio Europeo de Derechos Humanos. Madrid: Centro de estudios Políticos y Constitucionales.

Bocanegra, R. (2012). Lecciones sobre el acto administrativo. Cuarta Edición. Cizur Menor (Navarra): Civitas - Thomson Reuters.

Calvo, M. J. (2000). La función social de la propiedad y su proyección en el sistema de compensación urbanística. Salamanca: Ediciones Universidad de Salamanca.

Congreso de Colombia. (22 de diciembre de 1993). Ley del Medio Ambiente. [Ley 99 de 1993].

. (1 de enero de 1989). Normas sobre planes de desarrollo municipal, compraventa y expropiación de bienes. [Ley 99 de 1989].

. (18 de julio de 1997). Modificación de la Ley 9 de 1989 y la Ley 2 de 1991. [Ley 388 de 1997].

Consejo de Europa. (1950) Convenio Europeo para la Protección de los Derechos Humanos y de las Libertades Fundamentales. Recuperado de: http://www.echr. coe.int/Documents/Convention_SPA.pdf

. (1952). Protocolo Adicional al Convenio Para la Protección de los Derechos Humanos y de las Libertades Fundamentales. Recuperado de: http://www.derechoshumanos. net/Convenio-Europeo-de-Derechos-Humanos-CEDH/1952-Protocolo01-Convenio ProteccionDerechosHumanosyLibertadesFundamentales.htm

Consejo Nacional Legislativo. (15 de abril de 1887) Sobre adopción de Códigos y unificación de la legislación Nacional. [Ley 57 de 1887]. 
Constitución de Cádiz [Const.] (1812). Recuperado de: http://www.congreso.es/portal/ page/portal/Congreso/Congreso/Hist_Normas/ConstEsp1812_1978/Const1812

Constitución de la Segunda República Española [Const.] (1931). Recuperado de: http://www.congreso.es/portal/page/portal/Congreso/Congreso/Hist_Normas/ ConstEsp1812_1978/Const1931

Constitución Española [Const.] (1978). Recuperado de: http://www.congreso.es/docu/ constituciones/1978/1978_cd.pdf

Constitución política de Colombia [Const.] (1991) 2da Ed. Legis.

Corona Española. (24 de julio de 1889). Código Civil Español. [Real decreto.] BOE N²06.

Corte Constitucional de Colombia. (9 de junio de 1993). Sentencia C-216. [MP José Gregorio Hernández Galindo].

. (18 de agosto de 1999). Sentencia C-595. [MP Carlos Gaviria Díaz].

_. Sala Primera (15 de diciembre del 2005). Sentencia T-1321/05. [MP Jaime Araujo Rentería].

_. Sala Plena. (15 de marzo del 2006). Sentencia C-189. [MP Rodrigo Escobar Gil].

. Sala Séptima de Revisión. (27 de julio del 2011). Sentencia T-580/11. [MP Jorge Ignacio Pretelt Chaljub].

Escuin, V. (2008). Comentarios a la ley de expropiación forzosa. Tercera Edición. Cizur Menor (Navarra): Thomson - Civitas.

Fayos, J.L., Pérez, J.L., Sancho, J.A., Morote, J.V., Reig, G. (2012). Expropiación Forzosa Urgente. Tercera Edición. Madrid: La Ley- Wolters Kluwer España S.A.

Fernández, J.R. (2007). Estudio integral de las expropiaciones Urbanísticas. Segunda Edición. Cizur Menor (Navarra): Thomson- Aranzadi.

García, E. (2006). Los Principios de la nueva ley de expropiación forzosa. Cizur Menor (Navarra): Thomson Civitas.

García, E. (2008). Curso de Derecho Administrativo II. Undécima Edición. Madrid, Civitas Ediciones S.L. 
García, F.M. (2007). El derecho de propiedad en la constitución española de 1978. Santiago de Cali: Criterio Jurídico/Pontificia Universidad Javeriana de Cali, 281-294. Recuperado de http://dialnet.unirioja.es/servlet/articulo?codigo=2668487

Secretaría General Alcaldía Mayor de Bogotá D.C. (5 de octubre del 2006) Declaración de interés público de predio. Concepto 030 de 2006. Dirigida a Salomón García Pineda [Manuel Ávila Olarte, Subdirector de conceptos].

Tribunal Constitucional, Pleno del Tribunal. (26 de marzo de 1987). Sentencia 37/1987. BOE $N^{\circ}$ 89. Recuperado de: http://hj.tribunalconstitucional.es/cs/Resolucion/ Show/769

Ruiz, J.A. (2014). Enajenación Voluntaria. Expropiación por Vía Administrativa. Segunda Edición. Medellín: Librería Jurídica Sánchez R, 69-76.

Velásquez, L.G. (2010). Bienes. Duodécima edición. Bogotá: Editorial Temis S., 199-213. 